\title{
A Review of Social Cognitive Theory and Self-care for Type 2 Diabetes Mellitus Patients
}

\author{
Nomahaza Mahadi (Corresponding author) \\ Azman Hashim International Business School, Universiti Teknologi Malaysia \\ Jalan Sultan Yahya Petra, 54100 Kuala Lumpur, Malaysia \\ E-mail: mahaza@ibs.utm.my
}

Siti Nurani Abdullah

Negeri Sembilan State Health Department, Jln Rasah, Bkt Rasah, 70300 Seremban

Negeri Sembilan, Malaysia

E-mail: nuraniabdullah87@gmail.com

Shathees Baskaran

Azman Hashim International Business School, Universiti Teknologi Malaysia

Skudai, Johor, Malaysia

E-mail: shathees@ibs.utm.my

Received: April 3, 2020 Accepted: April 21, 2020 Published: May 5, 2020

doi:10.5296/bms.v11i1.16961ＵRL: https://doi.org/10.5296/bms.v11i1.16961

\begin{abstract}
Diabetes could be very challenging to manage due to its high complication that could give negative impacts to patient's quality of life. Diabetes mellitus is a non-communicable chronic disease that has caused significant morbidity since ten years ago. Diabetes Mellitus treatment is essential to reduce disease complication. Adapting self-care behaviour based on theory can, therefore, be implemented as one of the effective ways of managing diabetes. Social Cognitive Theory has been one of the most common theories that used in many studies as to


improve behaviours in-patient with chronic disease such as diabetes mellitus. Furthermore, managing good self-care is very important in order to reduce the morbidity and mortality of diabetes patients, however diabetes self-care became a challenge to many people living with diabetes, as they need to adapt and learn self-care practices in their daily lives. Thus this paper would provide an understanding of the health care professional in delivering their self-care services, also helping oneself to stay healthy and control their disease by good self-care practices.

Keywords: self-care behaviour, quality of life, self-care practices, social cognitive design

\section{Introduction}

There were about 500 million cases of type 2 diabetes mellitus recorded worldwide in the year 2018 (Kaiser, Zhang \& Pluijm, 2018) and the number was expected to rise to 592 million by the year 2035 (Nanditha et al., 2016). An increment of $150 \%$ of type 2 diabetes mellitus cases is expected between the year 2000 and 2035 (Nanditha et al., 2016) in which $60 \%$ of the increment are contributed by the Asian region. The significant increase is due to ongoing and rapid transition of socioeconomic status in low- and middle-income countries (Nanditha et al., 2016) witnessing type 2 diabetes as the main aspect of the increment in global incidence. Therefore, additional support and continuous education for patients with type 2 diabetes mellitus had become a highlight when it comes to improving their quality of life and controlling the disease. Diabetic self-care became a challenge to many people living with diabetes as they need to adapt and learn self-care practices in their daily lives (Chan et al., 2015). In order to improve behaviours in patient with chronic disease such as diabetes mellitus, Social Cognitive Theory (SCT) has been one of the most common theories that used in many studies (Deborah et al., 2013). This theory consists of multiple constructs specifically self-efficacy, outcome expectation, knowledge, social support and self-regulation.

Previous research agreed that there was a significant relationship between age and knowledge of self-care of the patients. For example, as the age increases, the level of self-care knowledge decreases (Ming Yeong Tan, 2007). Other than knowledge, self-efficacy was also a major predictor for self-care behaviour (J.E.Lee et al., 2010) as it will bring about subsequent behaviour which influences the patient's judgement in doing any action afterwards (Glanz et al., 2008). Meanwhile, the expected outcome was a personal belief in the effect of an action in achieving a particular outcome (Lippke, 2017). Whereas, social support means receiving support from family, friends or any individual that could also affect their behaviour. The last one was self-regulation that important in controlling a person's process by determining goal setting, self-reward, self-monitoring, identification and self-instruction (M. Safari et al., 2009). All of these constructs are considered important in influencing behaviour of self-care in chronic diseases. In relation to this, self-care consists of certain process that should be done by diabetic patients daily to manage their disease more efficiently. It includes taking medicine at the correct time, practising proper and healthy diet, doing regular physical activity, regular self-monitoring of their blood glucose level and foot care (Shrivastava et al., 2013). However, patient's education on self-care would somehow be limited. It is 
worthwhile for the patients to take full attention during their self-care education by the healthcare practitioners so that they could practise self-care management at home. Therefore, this paper aims to discuss on SCT and self-care of type 2 diabetes mellitus patients as SCT becomes the basis of the behaviour and skills chosen by individual in executing the task, besides it approach individuals in view of doing a task in a goal-directed manner.

\section{Social Cognitive Theory and Self-Care}

The social cognitive theory (SCT) proposes that cognitive process could develop someone's behaviour. It is derived from the social acquisition of knowledge. The main idea behind this theory is that a person could self-manage their thoughts, behaviour as well as regulate their motivation (Bandura, 1998). SCT approach people in view of doing a task in a goal-directed manner and being proactive in shaping the task that was given to them (C. Hurleyy, 1992). Besides, SCT becomes the basis of the behaviour and skills chosen by the individual in executing the task (C. Hurleyy, 1992). In 1941, N. E. Miller and J. Dollard evolved social cognitive science (Bozack, 2011; Whitham et al., 2013). They carried out this theory in the field of social learning theory that was inspired by human behaviour and pushed the concept of reduction in which an individual would be driven by the biological need (Bozack, 2011). Bandura also researched observational learning and imitation as the main components of the theory of social learning (Bandura, 1969). The theory of social learning imparted observational learning as an effective method for any change in behaviour relative to direct instruction, and it did not need to be reinforced (Whitham et al., 2013).

Albert Bandura and Richard Walters explored human function through decades of research and extended the cognitive framework in 1963 to become a philosophy of social cognitive (Bozack, 2011). Bandura and Walters published their research that year as Social Learning and Development of Personality, which became the most detailed description of the theory of social learning. This demonstrated the efficiency of reinforcement control rather than subconsciously induced observational learning (Bozack, 2011). Bandura started renaming social learning theory to social cognitive theory in 1986 with the introduction of Social Thinking and Behaviour Foundations: a widely cited social cognitive theory of psychology (Dinesh et al., 2016). This demonstrated the vital role of the mechanism of cognitive behaviour that was not impacted by the theory of social learning (Bozack, 2011). He noticed through his research that the theory of social learning that he earlier named was not expansive enough to describe what he wanted to capture in social cognitive theory. The term 'learning' itself was too small to become SCT (Bandura, 1997 \& Bandura \& Walter, 1963).

Thus, based on Bandura (1998), the theory was the most researched one in the psychological field, with the most varied history covering psychology, the legal system, education, therapy, industry, exercise, and sport. Several similar standardized concepts are relevant to human behaviour. The meanings include self-organizing, self-reflecting and self-regulating from environmental incidents (Bandura, 1986). In fact, it was also influenced by social and internal factors that affect the self-development of an individual and how the person adapts to the environment (Bandura, 1986). By way of framing SCT, Bandura (1986) noted that "the social 
portion of the terminology acknowledges the social origins of much human thought and action; the cognitive portion recognizes the influential causal contribution of human thought processes to human motivation, affect, and action." Although the underlying framework was the same since 1986 Bandura has consistently used the term social cognitive theory as it represented all the components in a better and more comprehensive manner (Whitham et al., 2013). On the other perspective, SCT was focused on a person's unique ability to symbolize their interactions, develop their forethought about the consequences for their actions, benefit from the actions of other people, change their behaviour by self-regulation and then self-reflect on the basis of their actions (Bozack, 2011).

Past studies reported that the development of SCT consisted of awareness, self-efficacy to overcome obstacles, self-efficacy of activities, perceptions and values of performance, self-regulation, emotional adaptation, analytical learning (modelling), situational and emotional perception (Ghoreishi, Vahedian-Shahroodi, Jafari, \& Tehranid, 2019). In more recent by Schunk \& Usher (2019), it claimed that SCT was a psychological viewpoint on human behaviour on the basis of a social environment marked by inspiration, self-regulation and learning. The study focused on SCT, as Bandura (1986) suggested. It was commonly used in a variety of fields, including psychiatric practice, education, wellbeing and industry (Schunk \& Usher, 2019). Initially, SCT was also recognized as the theory of Bandura or the social cognitive theory of Bandura, which Zimmerman, Pajares and Usher eventually developed and evaluated in many different perspectives (Schunk \& Usher, 2019). Another SCT perspective of Thojampa (2017) centred on the experience of behaviour, an individual and environmental, social dimension that would eventually provide the participant with a concrete perspective. For future self-care activities, useful insight could be used (Thojampa, \& Mawn, 2017).

Several researchers have previously proposed a model of social cognitive theory in forecasting self-care among type 2 diabetes mellitus patients (Ghoreishi, Vahedian-Shahroodi, Jafari, \& Tehranid, 2019). Through this hypothesis, the patient's actions could then be influenced by their self-care regime (Ghoreishi et al., 2019). It had introduced predictors and principles that shape, motivate and assist the patient's behaviour in complying with self-care activities (Ghoreishi et al., 2019). SCT has been reported to have several constructs that include awareness, self-efficacy, expectations of results, social support, self-regulation, goals, potential facilitators and impediments (Wendling \& Beadle, 2015). In terms of shaping their encouragement and behaviour in self-care behaviours, these constructs should communicate with each other so that an individual retains the influence of their disease (Stacy Wendling, 2015). For instance, if an individual has ample faith in achieving the desired objectives, self-care practices are highly likely to be carried out.

\section{Concept of Self-Care Management}

Self-care is a series of tasks that create a collection of skills. Understanding the principles of self-care are developed from two contrasting viewpoints was important; individual self-care, and how self-care is linked to the health system. This would, therefore, be named either 


\section{Macrothink}

focused on individuals or based on the framework. Both situations are interrelated as an individual needs to determine what they want to do to improve their health as well as to use the appropriate health tool excellently to protect and maintain their health.

It emphasizes the needs for self-fulfilment, the psychological needs and the individual's self-empowerment in the context of people-centred care. Briefly, self-care lets someone create their own "health assets". The fundamental self-care viewpoint was a "system-centred" approach that focused on some things that can help patients cope with their condition. It was also outlined in the Kaiser Permanente ladder, revealing self-care as a distinct type of complementing traditional healthcare (M Narasimhan et al., 2019).

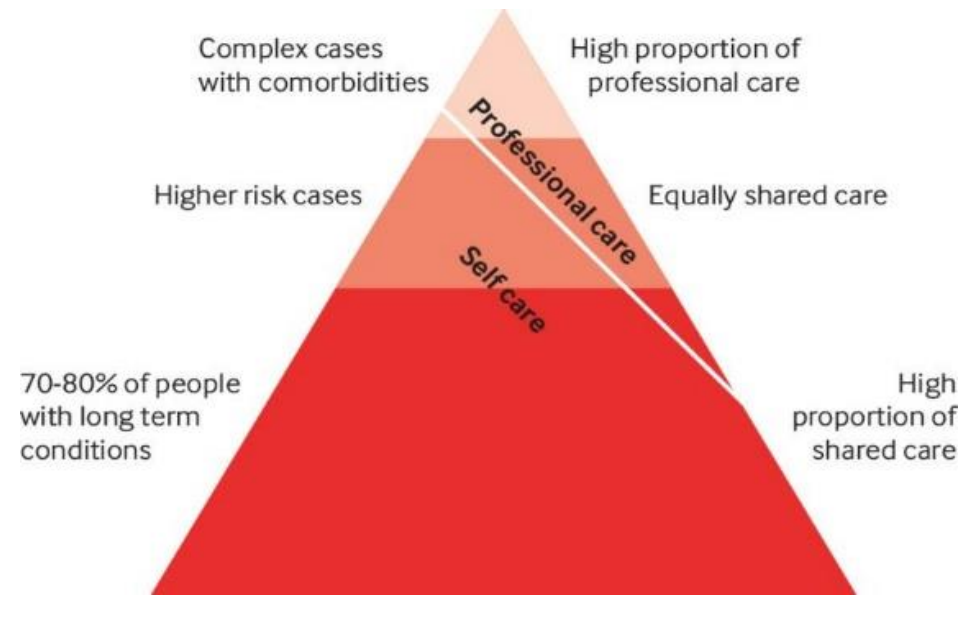

Source: Narasimhan et al. (2019)

Figure 1. Kaiser Permanente Pyramid: Health system perspective on the relationship between self and professional care

Depending on this structure, from the viewpoint of the health system, there was a large portion of self-care. $70-80 \%$ of patients with long-term chronic diseases such as diabetes mellitus require regular self-care to maintain good health and improve their quality of life. Inside the health system, there was also a significant portion of professional care available to treat particularly high-risk patients of comorbidities. The coordination of professional care and self-care could strengthen the health care system, especially for chronic disease management (M Narasimhan et al., 2019).

\section{Diabetes Overwhelmus}

It was a term describing diabetes as a persistent, painful demand with uncertain consequences. Demand for disease management overwhelms most diabetic patients (Richard R. Rubin, 2001). Based on a study performed in the Diabetes Control and Complication Study, not all patients maintain healthy blood sugar control given their continued support and inspiration during the trial. There is no assurance that all the factors affecting blood glucose level and other risk factors can be appropriately controlled and handled. That is why the word diabetes 
is daunting.

As Richard R. Robin (2001) mentioned, diabetes overwhelmus could cause a negative cascade. If an individual with diabetes feels overwhelmed, they may probably not participate in self-care practices. A few patients were giving up doing all the activities, but most of them would slowly reduce self-care good habit and turn out not to do it anymore. Their activity would, therefore, contribute to suboptimal regulation of blood sugar, far from ordinary. As a consequence, it raised patients' emotional burden such as remorse along with an increase in a physical strain that further aggravated diabetes overwhelmus. Richard R. Rubin (2001) claimed that this was the main barrier to good self-care.

The next idea from this term was "sticking point". It could be identified by a specific question questioning diabetic patients. For example, patients said, "If I watch television at night, I cannot resist snacking". Therefore, the real problem that could snap away their hope and cause crippling diabetes was such a "sticking point". Healthcare professionals were, therefore, able to tackle the issue and provide them with the appropriate solution. There have been occasions where people cannot reach a sticking point. They could say when questioned, "Everything!" By narrowing down the question, healthcare professionals should be more innovative, and they might reply, "My diet!" The "sticking point" term could be used and handled correctly from there. Self-care practices could be carried out gradually, step by step, through this definition.

Another way to avoid diabetes overwhelmus was to consider whether or not the patients were physically drained. Depression may result from severe emotional exhaustion. The condition could be handled by supplying and managing the patients with a stress screening questionnaire. Therefore, screening patients for depressive symptoms was significant. Relieving some psychological symptoms may cause a beneficial cascade of actions and emotions as well as improve metabolic output via self-care behaviours.

\section{Self-Care and Diabetes Mellitus}

Self-care in diabetes mellitus, together with the growth of diabetic awareness, was described as an emerging process of learning the ability to cope with the disease in a social context. Most of the self-care treatments of diabetic patients come with the support of their relatives (Etzwiler, 1994). It was, therefore, critical to have a reliable metric for diabetes self-care. This requires eating a healthy diet, regular blood sugar testing, getting physically active, having excellent problem-solving and coping skills, dealing with diabetic medicine, and having good risk-reduction habits (Fadayevatan, 2017). All of these interventions are useful in treating diabetic patients for physicians and experts and assessing a self-care strategy. Studies have shown that it is improving life quality (Shrivastava, 2013). In order to achieve a good clinical result, self-care management allows people to adhere to a healthy lifestyle adjustment and follow a healthy diet. In addition, the role of clinicians and other healthcare personnel in providing education and maintaining a high level of self-confidence to promote positive behavioural change was also critical (Shrivastava, 2013). 


\subsection{Self-Care Education}

Education in self-care was instrumental in treating diabetes because there was proof that those patients participating in their management will have an excellent dramatic effect on their disease progression (UKPDS, 1998). Those with better knowledge of their condition would then have a stronger progression of the disease of self-care. William, Freedman and Deci (1998) conducted a study that represented self-care treatment for type 2 diabetic patients during subsequent follow-up. Nonetheless, the effect diminished after the therapy ended for several months, suggesting that a continuation of self-care education was required. To conclude, proper self-care management will lower the level of Hemoglobin A1c (HbA1c) forecasting the good clinical result (Shrivastava, 2013; Kang Chia Yee, 2018).

\subsection{Self-Care Activities}

While self-care education in diabetes has been shown to enhance health results, it needs to be put into practice to optimize benefits truly. Self-care practices include, as mentioned earlier, following a healthy diet, increasing exercise, foot care, eliminating high-fat diets and controlling self-blood glucose. The ultimate goal of good self-care is to lower the level of glycosylated haemoglobin expressed by HbA1c. Nevertheless, to improve the quality of life, it also needs consistency with behavioural changes.

One of the primary self-care practices is blood glucose (SMBG) level self-monitoring. Routine surveillance aims to determine the overall glycaemic performance so that the next effective intervention can be scheduled promptly. SMBG provides up-to-date information on glycaemic status, enabling the clinician to adjust medication, dietary advice and exercises to achieve an optimal outcome. In fact, regular physical exercise in diabetic patients has also been shown to improve health results (Shrivastava, 2013).

\subsection{Self-Care Compliance}

In managing their disease, a diabetic patient needs to follow a particular set of daily behavioural actions. The activities involve participating in diet or physical activity, adopting a healthy meal schedule, taking insulin or oral hypoglycaemic treatment, accompanied by SMBG, following guidelines on foot care, reacting to diabetic-related symptoms and how to cope with them and seeking medical care where required. With the need to incorporate all these things into their daily routine, the entire list of self-care has been incorporated.

Through strengthening their self-care practices, most patients with diabetes may substantially reduce their risk of experiencing complications over the long term (Shrivastava et al., 2013). It was not an easy task, in any case. Although it could produce a positive outcome, if their compliance with self-care practices were low, patients could not be criticized (Anderson et al, 2000). Karimy et. al (2018) found that only 30 per cent of patients with diabetes complied with the therapy, while the remaining patients did not comply with their medicine. Most of them come from disadvantaged socio-economic groups.

Patients were willing to make improvements in their conduct, in one of the American 
experiments, when each procedure was independently enforced. Several studies (Shrivastava et al., 2013) have therefore indicated that healthcare professionals could incorporate and track self-care practices depending on the ability and desire of the individual to partake in the behaviours.

\subsection{Self-Care Barriers}

There were different obstacles that we need to search for when introducing an effective self-care plan for a diabetic patient. When providing treatment to the diabetic patient, the position of clinician and other healthcare workers was remembered. Nonetheless, it is also essential to consider such causes, such as cultural and sociodemographic obstacles, such as patient satisfaction concerning medical care, inadequate access to drugs and diagnosis, degree of complications, patient-provider relationships, high treatment costs, and rural areas that hinder self-care practices mainly in developing countries (Norris SL et al., 2002).

From a patient viewpoint, obstacles may be from patient commitment to care, disposition, conviction, language barriers by which patients are unable to comprehend provider details, lack of knowledge of diabetes, comorbidities, limited financial means, and social support (Sohal et al., 2015). While, from the viewpoint of the providers, patients are inexpensive in getting the treatment and the provider has no confidence in their ability to change the behaviour of the patient (Chin MH et al., 2001).

\section{Conclusion}

Self-care became part of a critical aspect of Diabetes Mellitus treatment. It was part of a potential change in cognitive behaviour (Ghoreishi et. al., 2019). Thus, when it could clarify how behaviour changed, the social cognitive came into the picture. This implemented a series of predictors that could affect the nature of self-care actions among individuals. Not only has Social Cognitive Theory helped shape the behaviour, but it has also been able to lead and inspire people in line with good self-care habits (Ghoreishi et. al., 2019). Social Cognitive Theory also developed a good model that relies on individual behaviour learning interactions that have been widely accepted in much previous research (Koo et. al, 2011).

Diabetes mellitus has become one of the world's most significant health issues (Yonas, Debela \& Fekadu, 2018). Over the past decade, there has been a growing trend in the number of people living with diabetes mellitus from 108 million in 1980 to 422 million in 2014 (WHO, 2016). Therefore, from 4.7 per cent globally, the incidence of diabetes mellitus had doubled to 8.5 per cent (WHO, 2016). It is a chronic disease that can cause severe heart, eyes, nerve, kidney, and blood vessel problems (WHO, 2016 and Yonas et al., 2018). This happens because insulin deficiency occurred; a hormone that was secreted inside the body by the pancreas could not regulate blood glucose (Yonas et al., 2018). Type 2 diabetes mellitus is a preventable disease (WHO, 2016). Even if it happens, it could be effectively managed as long as the patients fulfil good self-care practices (F.S. Bosun-Arije et al., 2019). The main component of diabetes management is self-care (Zeinab Jannoo \& Naushad Mamode Khan, 
2019). The self-care process of diabetes has been very complex, as it also requires family members' intervention (Zeinab Jannoo et al., 2019). In order to prevent infections, the obligation for treating and monitoring the disease became necessary for type 2 diabetes mellitus patients (Zeinab Jannoo et al., 2019). Diabetes mellitus self-care treatment applied to any patients who were considered to have diabetes mellitus. Through incorporating positive behavioural changes as well as symptoms and diagnosis of the illness, they became responsible for managing their condition (Thojampa \& Mawn, 2017). Ideally, patients with diabetes mellitus should perform self-care as part of their daily activities to improve health outcomes and to prevent serious complications in the future.

\section{References}

Bozack, A. (2011). Social Cognitive Learning Theory. Encyclopedia of Child behaviour and Development. pp 137-162.

Bandura, A. (1997). Self-efficacy: the exercise of control, International collaborative research on management self-efficacy in diabetes mellitus. Journal New York Nurses Assoc., 27, 9-14.

Bandura, A. (1998). Health Promotion from the Perspective of Social Cognitive Theory. Psychology and Health, 13, 623-649.

Bandura, A. (2001). Social Cognitive Theory of Mass Communications, In J. Bryant, \& D.Zillman (Eds.). Media effects: Advances in theory and research. Hillsdale, NJ: Lawrence Erlbaum., 2, 121-153

Hurley, A. C., \& Shea, C. A. (1992). Self-Efficacy: Strategy for Enhancing Diabetes Self-Care. The Diabetes Educator, 18(2), 146-150. https://doi.org/10.1177/014572179201800208

Chin, M. H., Cook, S., Jin, L., Drum, M. L., Harrison, J. F., \& Koppert, J. (2001). Barriers to providing diabetes care in community health center. Diabetes Care, 24(2), 268-274.

Anderson, R. M., Funnell, M. M., Fitzgerald, J. T., \& Marrero, D. G. (2000). The diabetes empowerment scale: a measure of psychosocial self-efficacy. Diabetes Care, 23, 739-743.

Dinesh, P., Kulkarni, A., \& Gangadhar, N. (2016). Knowledge and self-care practices regarding diabetes among patients with Type 2 diabetes in Rural Sullia, Karnataka: A community-based, cross-sectional study. Journal of Family Medicine and Primary Care, 5(4), 847. https://doi.org/10.4103/2249-4863.201176

Deborah, L., Dewar, David, R. L., Philip, J. M., \& Ronald, C. P. (2013). Development and Evaluation of Social Cognitive Measures Related to Adolescent Physical Activity. Journal of Physical Activity and Health, 10, 544-555

Etzwiler, D. D. (1994). Diabetes translation: a blueprint for the future. Diabetes Care, 17(1), $1-4$.

Fadayevatan, R. (2017). Predictors of Self-care among the Elderly with Diabetes Type 2: 
Using Social Cognitive Theory. Diabetes \& Metabolic Syndrome: Clinical Research \& Reviews, 11(3), 163-166. https://doi.org/10.1016/j.dsx.2016.08.01

Ghoreishi, M.-S., Vahedian-Shahroodi, M., Jafari, A., \& Tehranid, H. (2019). Self-care behaviors in patients with type 2 diabetes: Education intervention base on social cognitive theory. Diabetes \& Metabolic Syndrome: Clinical Research \& Reviews, 13(3), 2049-2056. https://doi.org/10.1016/j.dsx.2019.04.045

Glanz, K., B. K. Rimer, F. M. Lewis. (2002). Health Behavior and Health Education. Theory, Research and Practice, Wiley \& Sons. San Francisco.

Griethuijsen, R. A. L. F., Eijck, M. W., Haste, H., Brok, P. J., Skinner, N. C., Mansour, N., et al. (2014). Global patterns in students' views of science and interest in science. Research in Science Education, 45(4), 581-603. https://doi.org/10.1007/s11165-014-9438-6.

Lee, J. E., Han, H. R., Song, H., Kim, J, Kim, K. B., Ryu, J. P., \& Kim, M. T. (2010). Correlates of self-care behaviors for managing hypertension among Korean Americans: a questionnaire survey. International Journal. Nursing Studies, 47, 411-417

Chan, J., Demelo, M., Gingras, J., \& Gucciardi, E. (2017). Challenges of Diabetes Self-Management in Adults Affected by Food Insecurity in a Large Urban Centre of Ontario, Canada. Food Insecurity and Disease, 159-178. https://doi.org/10.1201/9781315365763-10

Kaiser, A. B., Zhang, N., \& Pluijm, W. V. D. (2018). Global Prevalence of Type 2 Diabetes over the Next Ten Years (2018-2028). Diabetes, 67(Supplement 1). https://doi.org/10.2337/db18-202-lb

Kang, C. Y., Salmiah, M. S., \& Rosliza, A. M. (2018). Identifying self-care behaviour and its predictors among type 2 diabetes mellitus patients at a district of NorthernPeninsular Malaysia. Malaysian Journal of Medicine and Health Sciences, 14(2), 17-29.

Koo, M, Lee, M. H., Chang, Y., Huang, C. F., Chen, S. C., \& Yeh, Y. C. (2011). Factors associated with self care behaviors in middle age adult and elderly with diabetes mellitus. National Institute of Health, 58(5), 43-52.

Karimy, M., Koohestani, H. R., \& Araban, M. (2018). The association between attitude, self-efficacy, and social support and adherence to diabetes self-care behavior. Diabetology \& Metabolic Syndrome, 10(1). https://doi.org/10.1186/s13098-018-03866

Lippke, S. (2017). Springer International Publishing V. Zeigler-Hill, T.K.

Narasimhan, M., Allotey, P., \& Hardon, A. (2019). Self care interventions to advance health and wellbeing: a conceptual framework to inform normative guidance. British Medical Journal, 365, 1688

Monica, H. (2018). Self care Self regulation. Journal of Interdisciplinary Research.

Ming, Y., Tan, J. M. (2008). Self-care practices of Malaysian adults with diabetes and 
suboptimal glycemic control. Patient Educ. Couns., 72, 252-67.

Nanditha, A., Ma, R. C., Ramachandran, A., Snehalatha, C., Chan, J. C., Chia, K. S., \& Zimmet, P. Z. (2016). Diabetes in Asia and the Pacific: Implications for the Global Epidemic. Diabetes Care, 39(3), 472-485. https://doi.org/10.2337/dc15-153639

Norris, S. L., Lau, J, Smith, S. J., Schmid, C. H., \& Engelgau, M. M. (2002). Self-management education for adults with type-2 diabetes: a meta-analysis of the effect on glycemic control. Diabetes Care, 25(7), 1159-1171.

Richard, R. R. (2001). Facilitating Self-Care in People with Diabetes. American Diabetes Association. Diabetes Spectrum 2001, 14(2), 55-57. https://doi.org/10.2337/diaspect.14.2.55

Thojampa, S., \& Mawn, B. (2017). The moderating effect of social cognitive factors on selfmanagementactivities and HbA1c in Thai adults with type-2 diabetes. International Journal of Nursing Sciences, 4, 34-37.

Schunk, D. H., \& Usher, E. L. (2019). Social Cognitive Theory and Motivation. The Oxford Handbook of Human Motivation, 9-26. https://doi.org/10.1093/oxfordhb/9780190666453.013.2

Sheldon, C., Lynn, G. U., Benjamin, H. G. (2000). Social Support Measurement and Intervention: A guide for health and social scientist. Oxford University Press. pp1-4.

Shrivastava, S., Shrivastava, P., \& Ramasamy, J. (2013). Role of self-care in management of diabetes mellitus. Journal of Diabetes \& Metabolic Disorders, 12(1), 14. https://doi.org/10.1186/2251-6581-12-14

Sohal, T, Sohal, P, King-Shier, K. M., \& Khan, N. A. (2015). Barriers and Facilitators for Type-2Diabetes Management in South Asians: A Systematic Review. PLoS ONE, 10(9), e0136202. https://doi.org/10.1371/journal. pone.0136202

UKPDS: Intensive blood-glucose control with sulphonylureas or insulin compared with conventional treatment and risk of complications in patients with type 2 diabetes (1998) $U K$ Prospective Diabetes Study Group (UKPDS 33). 352(9131):837-853.

Wendling, S., \& Beadle, V. (2015). The relationship between self-efficacy and diabetic foot self-care. Journal of Clinical \& Translational Endocrinology,2(1), 37-41. https://doi.org/10.1016/j.jcte.2015.01.001

Williams, G. C., Freedman, Z. R., \& Deci, E. L. (1998). Supporting autonomy to motivate patients with diabetes for glucose control. Diabetes Care, 21(10), 1644-1651.

WHO, Geneva: Switzerland. (2010). World Health Organisation. Definition of an older or elderly person. http://www.who.int/healthinfo/survey/ageingdefnolder/en/index.html

Yonas, G., Debela, G., \& Fekadu, A. (2018). Factors associated with self-care practice among adult diabetes patients in West Shoa Zone, Oromia Regional State, Ethiopia. British Medical 


\section{Macrothink}

Business Management and Strategy ISSN 2157-6068

Council Health Services Research, 18, 732. https://doi.org/10.1186/s12913-018-3448-4

Zeinab, J., Naushad, M. K. (2019). Medication Adherence and Diabetes Self-Care Activities Among Patients With Type 2 Diabetes Mellitus. Value in Health Regional Issues, 18, 30-35.

\section{Copyright}

Copyright for this article is retained by the author(s), with first publication rights granted to the journal.

This is an open-access article distributed under the terms and conditions of the Creative Commons Attribution license (http://creativecommons.org/licenses/by/4.0/). 